\title{
Unison or cacophony: postgraduate training in pathology in Europe
}

\author{
Fred T. Bosman • Jan G. van den Tweel
}

Received: 8 February 2009 /Accepted: 10 February 2009 / Published online: 3 March 2009

(C) Springer-Verlag 2009

\begin{abstract}
With the free movement of people in the European Union, medical mobility has increased significantly. This is notably the case for disciplines for which shortage of well-trained staff has occurred. Pathology is among those specialties and effectively the discipline is confronted with a striking increase in mobility among trainees and qualified specialists. The presumption underlying unlimited mobility is that the competencies of the medical specialists in the European countries are more or less equal, including significant similarities in the postgraduate training programs. In order to assess whether reality corresponds with this presumption, we conducted a survey of the content and practice requirements of the curricula in the EU and affiliated countries. The results indicate a striking heterogeneity in the training program content and practice requirements. To name a few elements: duration of the training program varied between 4 and 6 years; the number of autopsies required varied between none at all and 300; the number of biopsies required varied between none at all and 15,000. We conclude that harmonization of training outcomes in Europe is a goal that needs to be pursued. This will be difficult to reach through harmonization of training programs, as these are co-determined by political, cultural, and administrative
\end{abstract}

\footnotetext{
F. T. Bosman ( $\bowtie)$

Institut Universitaire de Pathologie,

Centre Hospitalier Universitaire Vaudois,

Rue du Bugnon 25,

1011 Lausanne $(\mathrm{CH})$, Switzerland

e-mail: fred.bosman@chuv.ch

J. G. van den Tweel

Department of Pathology, University of Utrecht Medical Center,

Utrecht, The Netherlands
}

factors, difficult to influence. Harmonization might be attained by defining the general and specific competencies at the end of training and subsequent testing them through a test to which all trainees in Europe are subjected.

Keywords Postgraduate education · Europe

\section{Introduction}

The European Union and its affiliates counts about 30 countries that are all entirely autonomous regarding underand postgraduate medical education, licensing, specialty diplomas, and CME. In these countries postgraduate training programs for the medical specialties are usually under regulation by government supervised governing bodies, in which (a variety) of medical specialties are represented. Representatives tend to be delegated by a professional society, which typically has created a committee for postgraduate education, in charge of defining program content and monitoring training outcome, the latter often in the format of an examination. The responsible professional societies may be largely practice oriented, or more academically or both. In practice, those who bear academic responsibility for postgraduate education are often not necessarily represented in these governing bodies.

According to EU legislation, any member-country is obliged to recognize the medical certificates of any other member-country as equivalent. This has stimulated reflection as to how to get to an integrated European approach, within the Union Européenne des Médecins Spécialistes (UEMS). The backbone of UEMS are the 37 Specialist Sections and the corresponding European Boards, representing the majority of European specialties. Specialist Sections, including pathology, are composed of two 
delegates per member state who represent the national professional organization for medical specialists in a particular specialty. How delegates are appointed varies per country. Sections may admit additional members with specific expertise. For example the Section/Board of Pathology includes representatives of the European Society of Pathology, the European Association of Junior Doctors, the European Federation of Cytological Societies in combination with the International Academy of Cytology, Forensic Pathology and the European Confederation of European Neuropathological Societies (Euro-CNS).

As yet, the Section/Board has made several attempts to harmonize training programs and developed the European Pathology Board Examination, an MCQ test assessing basic knowledge and morphological recognition skills that every practicing pathologist should dispose of. The examination was originally only intended for pathologists certified in one of the EU countries. For several reasons they hardly participate in this examination. As a matter of fact, nearly all participants are non EU (in the 2008 test 32 out of 35) candidates who hope to gain access to pathology practice in an EU member state. This raises the question whether this examination still makes sense as a European test.

How pathology trainees in the EU acquire their knowledge and skills is left entirely up to the specialty boards in the individual member-countries. As evidencebased principles in diagnostic pathology are far from universally applied [1] this potentially constitutes and important risk for heterogeneous pathology practice. The EU has no common definition of basic training requirements nor have common rules for the accreditation of training institutions been developed.

In this structure, primary responsibility for the conception of a European framework for supranational curriculum planning is formally confided to UEMS pathology. In practice, however, UEMS pathology is lacking in executive power. The pathologists representing national governing bodies or professional societies in the UEMS Section and Board are not necessarily those directly responsible for the national training program and do not necessarily have key academic affiliations or responsibilities. Consequently, the Section/Board disposes of little means to impose a supranational vision on national governing bodies, which remain largely autonomous. This complexity, the significant lack of congruence between academic and administrative responsibilities and the prevalence of national regulations over supranational aspirations, has hampered the development of a common blueprint for postgraduate education in pathology.

However, harmonization remains an important goal, as increasing mobility in the pathology field is a reality, given the shortage of pathologists in most European countries. A recent initiative to overcome this problem has been the creation of the European Association of Pathology Chairs and Program Directors (EAPCP), which has brought together those directly responsible for under- and postgraduate pathology education.

Curious as to the real bandwidth of qualifying criteria, against the background of this lack of common ground, we set out to obtain details of the postgraduate training programs in pathology for the member countries and (potentially) affiliated countries of the European Union. A questionnaire was sent to national representatives, for a number of countries several representatives, with the aim to verify if within a single country 'unity of doctrine' exists in reality. This paper reports on the results of this survey and proposes strategies that might be explored in order to attain the necessary harmonization in training outcomes.

\section{Materials and methods}

A questionnaire was developed (Table 1) and sent to a representative of each country represented in the European Section/Board of Pathology. In case of non-response, a reminder was sent and for some countries additional contacts were addressed in order to obtain a complete data set. Personal interactions with representatives from most countries clarified open issues and provided additional detail where deemed necessary.

\section{Results}

The response rate was high: we obtained an appropriately completed questionnaire from 26 of 30 EU and affiliated countries. In some countries, we received several slightly different responses in view of their decentralized approach to postgraduate training regulation (e.g., in Germany, confided to the 'Länder'). The complete dataset is provided as supplementary information (supplement 1). From eight countries, we obtained the URL of a website where detailed information concerning qualifying requirements and training programs can be obtained. These are likewise contained in the supplementary information.

Program duration, overall structure

The minimum required duration of postgraduate training varies between 4 (eight countries) and 6 (one country) years (Table 2). In most (17) countries the duration is 5 years, but 6 years in one country. In eight countries, clinical training is required (mostly 1 year, but 6 months in one country), which may (for 6-year training programs) or may not (for 4-year training programs) be included in the overall listed duration. Remarkably, the 4-year programs are mostly in the 'new' European member countries. 
Table 1 Survey EAPCP

Structure of the postgraduate training program in Pathology in the European countries

1. Is pathology one specialty in your country or are there recognized subspecialties: if subspecialties which:

cytopathology

one several neuropathology molecular pathology other

2. How long is postgraduate training in pathology (general anatomic/diagnostic pathology) in your country?

\section{4} 5 $-6$

yes 7 years

3. Is a year of clinical training required?

4. Has your specialty governing board developed detailed guidelines for specialty training, including learning objectives and practice requirements? yes yes yes Accessible on a Website? yes

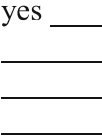

yes no how many autopsies are foetal autopsies counted? cytology biopsies frozen sections how many how many
Are there set minimum numbers for subspecialty areas? If yes, please specify:

6. For which of the following techniques is hands on experience required in your programme:

- routine histology

- immunohistochemistry

- morphometry

- in situ hybridization

- molecular biology

- electron microscopy

7. Are theoretical courses an important part of your postgraduate programme If yes, what is the number of course hours required per year? Can you provide a course programme?

8. Are residents supervised during the entire training period or do they develop an increasing level of autonomy during their residency?

- supervised all along

- gradual increase in autonomy

- do they independently sign reports

9. Are residents required to participate in a research project? Do they have to publish (a)paper(s) in order to qualify for a specialist diploma?

$\begin{array}{ll}\text { yes } & \text { no } \\ \text { yes } & \text { no } \\ \text { yes } & \text { no } \\ \text { yes } \_ & \text {no } \\ \text { yes } & \text { no }\end{array}$

yes yes

no 
Table 1 (continued)

10. Does your country require a specialty examination?

yes

no

If yes, how is this composed?

MCQ theoretical test

Open question test

Slide seminar histology

Slide seminar cytology

Cutting in with histology and writing a full report

Autopsy, including writing a full report

11. How are residents selected (match, interview)

Are residents regularly evaluated, how (specify)

Is there a nationwide regular (for example annual) progress examination (anonymous or

nominative)

Do residents have to participate in quality control surveys

Do residents perform the histological examinations for all the cases examined

macroscopically?

Are residents required to present cases in clinico-pathological conferences?

Do residents regularly participate in international courses/conferences?

Any other comments?

Please provide documentation (in English preferably) whenever available.

In 20 countries, obligatory courses are part of the training program, eight of these without specification of the number of course hours for the total training program. For the other eight, the number of course hours varied between 48 and 300 per year.

With few exceptions, the reaction to the question whether or not the trainee developed a certain level of autonomy during the program was affirmative. Strikingly, however, on the question whether or not the trainee was allowed to sign out cases without supervision, the response was mostly negative: in only eight countries residents are allowed to sign out cases autonomously before final qualification.

\section{Practice requirements}

Remarkable heterogeneity characterizes the practice requirements for certification (Table 3). Most countries specify some level of activity for specific fields, although in six countries no numbers are set. This obviously does not imply that a trainee can qualify without having practiced diagnostic pathology; the responsibility for judging an adequate level of proficiency may be ultimately left to the director of the training program and/or the final program examination (Table 4).

For autopsies the required numbers varies between 60 and 300. In most countries fetal autopsies are included in the autopsy count, although for some countries a maximum number of fetal autopsies in the total count has been set. In at least two countries (France and Greece), qualification as specialist pathologist can be obtained (almost) without any autopsy practice. For biopsies the required number varies between 600 and 15,000. In two countries (Switzerland and Lithuania) the number of biopsies within subspecialty fields is defined. For cytology the numbers required varies between 500 and 10,000. In several countries a specified

Table 2 Program duration and overall structure

\begin{tabular}{ll}
\hline & Number of countries \\
\hline Duration of training & 8 \\
4 year & 17 \\
5 year & 1 \\
6 year & \\
Clinical year required & 8 \\
Yes & $($ one 6 months) \\
& 18 \\
No & \\
Development of autonomy & 22 \\
Yes & 4 \\
No or ? & \\
Independent sign out before graduation & 8 \\
Yes & 18 \\
No or ? & \\
Obligatory courses & 18 \\
Yes & 8 \\
No or ? & \\
\hline
\end{tabular}


Table 3 Practice requirements

Number of countries

\begin{tabular}{|c|c|}
\hline \multicolumn{2}{|l|}{ Autopsies } \\
\hline None specified & 4 \\
\hline$<100$ & 1 \\
\hline $100-200$ & 19 \\
\hline$>200$ & 2 \\
\hline \multicolumn{2}{|l|}{ Biopsies } \\
\hline None specified & 6 \\
\hline$<3,000$ & 3 \\
\hline $3,000-10,000$ & 13 \\
\hline$>10,000$ & 2 \\
\hline \multicolumn{2}{|l|}{ Frozen sections } \\
\hline None specified & 16 \\
\hline$<100$ & 2 \\
\hline$>100$ & 5 \\
\hline \multicolumn{2}{|l|}{ Cytology } \\
\hline None specified & 6 \\
\hline$<3,000$ & 7 \\
\hline$>3,000$ & 11 \\
\hline \multicolumn{2}{|l|}{ Technical competencies } \\
\hline Histology & 12 \\
\hline Immunohistochemistry & 10 \\
\hline Electron microscopy & 7 \\
\hline Morphometry & 5 \\
\hline Molecular pathology & 3 \\
\hline FISH & 1 \\
\hline
\end{tabular}

number has been set for gynecological and non-gynecological cytology.

In most countries with explicit practice requirements, no numbers have been set for frozen section diagnosis. Effectively, in several countries frozen sections are not performed by trainees but only by qualified pathologists. In countries with specified numbers, these vary between 50 and 500 .
Exposure to laboratory methods in pathology

The questionnaire specified 'hands on' experience in laboratory methods. What exactly this implies is difficult to grasp from the survey documents. It can be assumed that in case of an affirmative answer at least some personal practice in the specific laboratory method is required. Many countries (14) require some practice in histological techniques and about the same proportion in immunohistochemistry (12). The number of countries requiring experience in electron microscopy (seven) or morphometry (five) is lower. Of note is that experience in molecular pathology is required in only five countries and in fluorescent in situ hybridization (FISH) in only 3.

\section{Examination}

The majority of the countries have over time adopted an examination system for quality control towards the end of the training period (Table 4). Nonetheless, in six countries, no central examination system exists and the director of the training program bears full responsibility for the certification of the candidate. In many countries the examination has a strong practice-oriented content. This might imply some form of testing of macroscopical examination skills and specimen sampling, included in nine countries. Reporting an autopsy, based upon a combination of examination of macroscopical specimens and the accompanying histology is included in 11 countries. Cytology slides and histology slides are almost invariably included in the examination (16 and 18, respectively; 14 out of 20 examining countries). Knowledge is tested through multiple choice questions in eight countries and through open questions in 13. Oral examinations were explicitly stated by two countries, although in reality this figure is probably higher as most practiceoriented examination parts tend to be conducted through direct interaction between an examiner and the candidate, which can be considered as a form of an oral examination.

Table 4 Final examination

\begin{tabular}{lllr}
\hline & Number of countries & Type of examination & Number of countries \\
\hline Without final examination & 6 & & MCQ \\
With final examination & 20 & Open questions & Of which oral \\
& & Cutting in & 2 \\
& & Histology & 9 \\
& & Cytology & 13 \\
& & Autopsy & 11 \\
With intermediate progress examinations & 4 (of which 1 anonymous) & & \\
\hline
\end{tabular}


In only four countries, intermediate 'progress' tests are organized, one of which anonymous underlining its formative character.

Research, selection, international exchange, and cpc participation

Research is not universally considered a priority: in only nine countries active participation in a research project is required and in only four countries a published paper is required in order to qualify as a specialist.

Selection of trainees is very different between the different countries. The extremes are, on the one end of the spectrum, the countries where freshly graduated physicians have to sit a national ranking test. Ranking according to the score determines access to specialty training: the higher the ranking, the more options are open. In this system, usually the trainees are assigned to a program and the director of the program has limited influence on the choice of candidate trainees. On the other end of the spectrum, fresh graduates apply for open trainee positions and the decision as to who to enlist is entirely taken by the director of the program. We do consider how graduates are selected for a training program an important issue. It is highly likely that the evolution of a training program is at least in part determined by the composition of the trainee group and therefore the selection process might have significant impact on the outcome of training.

International exchange seems not to be a priority, although many countries do promote and support participation in international courses. Most countries (20) advocate active participation of trainees in clinicopathological conferences, usually with the responsibility to present and discuss cases.

A final question was whether or not trainees perform microscopical examinations of all the cases for which they had assumed the macroscopical examination. The importance of the question is the tendency in some departments to use residents as an easy labor force for tasks regarded as less qualified, but that do not necessarily provide added value to the training program. In nine countries, residents routinely perform macroscopical examination of specimens which they do not see again for microscopical examination and of which they do not edit the report.

\section{Discussion}

Harmonization of pathology training has for nearly 20 years been the main aim of the Specialist Section/Board of Pathology of the UEMS. Despite the fact that the members of this body repeatedly agreed upon a common training and testing program, and were willing to support this in their national bodies, the proposed measures did not result in the intended harmonization and implementation of these initiatives in the national programs largely failed. In the meantime, in the EU the reciprocal recognition of certificates has resulted in a significant movement of European doctors, among whom many were pathologists, and the need for new initiatives to achieve the harmonization goal have become more and more evident [2]. We felt that detailed insight in the present training situation would allow us to develop more balanced efforts and better targeted actions. So what does the survey tell us?

First of all, heterogeneity in the training programs is striking. For none of the investigated items any sign of effective harmonization was perceived. The differences in training duration, training content, responsibilities of the trainees, research experience, and testing and examination appear to be enormous. It is evident that none of the wellintended initiatives in the past has resulted in any improvement of the existing diversity. The reasons for this failure lie primarily in the decentralized responsibility for postgraduate training and specialist certification: entirely at a national level. Most countries (understandingly) want to stick to their own concept of a program, which in their judgment has functioned well for decades. A striking conclusion is that some pathologists trained in Europe cannot assure adequate autopsy practice. This calls for explicit measures, as has been proposed for example in the form of a distinct subspecialty for autopsy pathology [3].

Secondly, pathology curricula in the European countries are still largely oriented towards classical pathology practice. The amount of exposure to new methods in diagnostic pathology (notably molecular pathology) is very limited and that in an era full of new challenges and plenty more to come in the 30 or so years that the average trainee will practice the discipline. Training programs ideally should continuously identify new needs and develop effective approaches towards responding efficiently to new requirements [4,5]. A more balanced mixture of formal teaching and the prototypical 'learning by doing' might need to be considered [6].

Thirdly, validation of training outcome is very heterogeneous. National exams, which are not even universally applied as a measure of quality control of training outcome, are very different in structure and content. This might be one reason why the gradual increase in autonomy, proclaimed by most countries, has not resulted in much functional autonomy: rare are the training programs allowing advanced trainees to sign out cases independently, the ultimate reflection of autonomy. Longitudinal case-based evaluation [7] might provide a formal basis for allowing an advanced resident to gain professional independence. A European approach towards pathology training outcome validation might also facilitate transatlantic competence recognition, as has been called for in this era of globalization [8]. 
We must conclude that harmonization of training programs is an illusion and should no longer be pursued. Moreover it is not the program, but the outcome that counts. Since the practice of pathology is relatively uniform in Europe (and around the world) a much more pragmatic and realistic approach would be to agree upon the competencies at the end of training and to develop tools to measure competencies all along the training period, as has been implemented elsewhere [7, 9-11]. The Resident in Service Examination, a similar approach, is now implemented in $100 \%$ of the training programs in the United States [12]. Following such approaches the profile of the European pathologist has been conceived by the EAPCP and tools to monitor training outcomes, aiming at the European profile, are in full swing development. The main tool for monitoring of training outcome will consist of a formative progress test that is histo- and cytopathology practice-oriented, deployed through the internet as was already advocated long ago [13], can be used by the residents on a voluntary and anonymous basis for selfevaluation, and by institutions for comparing overall outcome of their program with that of others. Moreover, such a test can also be used by practicing pathologists to compare their knowledge with that of their peers.

What to do? Sensing the need to face these challenges the EAPCP was created with as primary aim to mount a European network of professionals responsible for the quality and the execution of the pathology training program in their institutes. The survey this paper is based upon is one of the initiatives taken by the EAPCP. The results obtained have helped the EAPCP in developing a description of the profile of the European pathologist at the end of her/his training, in terms of general and specific learning objectives. The document includes general guidelines as to how to develop these outcome parameters into a curriculum and how to evaluate in a structured way the progress of the trainee all along the training period and provides the basis for a European progress test, which will allow trainees to self-evaluate and training bodies all over Europe to compare training outcomes. As the UEMS Section/Board of Pathology remains an important professional-political platform to consolidate such initiatives and increase their impact, the EAPCP needs to collaborate with it and in fact the UEMS Section/Board of Pathology has agreed to collaborate. This will assure proper input from the relevant stakeholders and allow adequate representation of the interests of pathology as a medical discipline. The EAPCP might eventually act as a bridge between the bodies that determine the fate of pathology in Europe: the European Society of Pathology providing scientific and educational input with its annual congresses and postgraduate education programs, the UEMS Section/Board of Pathology providing professional and political input at a European level and the national pathology organizations, powerful third party in this complex process.

Acknowledgements The authors wish to thank the representatives of the national postgraduate pathology training bodies for their help in collecting the data.

Conflicts of Interest None.

\section{References}

1. Wick MR, Bourne TD, Patterson JW et al (2005) Evidence-based principles and practices in pathology: selected problem areas. Semin Diagn Pathol 22:116-125

2. Ruiter DJ, Roald B, Underwood J, Prat J, UEMS Section of Pathology/European Board of Pathology (2004) Histopathology training in Europe: a lesson for other specialties? Virchows Arch 444:278-282

3. Van den Tweel JG (2008) Autopsy pathology should become a recognised subspecialty. Virchows Arch 452:585-587

4. Saikia B, Gupta K, Saikia UN (2008) The modern histopathologist: in the changing face of time. Diagn Pathol. 3:25-28

5. Marchevsky AM, Wick MR (2004) Evidence-based medicine, medical decision analysis, and pathology. Hum Pathol 35:11791188

6. Gallagher PJ, Dixon MF, Heard S, Moore JK, West KP (2003) An initiative to reform senior house officer training in histopathology. Hosp Med. 64:302-305

7. Ducatman BS, Ducatman AM (2006) Longitudinal case-based evaluation of diagnostic competency among pathology residents: a statistical approach. Arch Pathol Lab Med 130:188-193

8. Van Den Tweel J, Taylor CR (2002) Globalization of pathology training and examination: the time to begin is now. Hum Pathol 33:861-862

9. Lockard WT Jr, Lunz ME, Burke MD et al (1989) The first six years' experience with the pathology residents' in-service examination, 1983-1988. Am J Clin Pathol 92(4 Suppl 1):S11-S22

10. Association of Directors of Anatomic, Surgical Pathology (2003) Curriculum content and evaluation of resident competency in anatomic pathology: a proposal. Hum Pathol 34:1083-1090

11. Wick MR (2003) Curricula for pathology training: an editorial comment. Hum Pathol 34:1091

12. Alexander CB (2006) Pathology graduate medical education (overview from 1926 to 2005). Hum Pathol 37:923-928

13. Hamza S, Anderson P, Reddy VV et al (2001) Use of the Internet in pathology resident training and education. Adv Anat Pathol $8: 290-297$ 